\title{
A Tecnologia da Informação como Viabilizadora da Divulgação Transparente e Eficaz de Dados Públicos
}

\author{
Célio I. C. Rodrigues', Raffael C. Rodrigues ${ }^{1}$, Nathalia Freitas de Menezes ${ }^{2}$, Igor \\ Oliveira Vasconcelos ${ }^{3}$
}

\author{
${ }^{1}$ Sistemas para Internet - Universidade Tiradentes (UNIT) - Aracaju, SE - Brasil \\ ${ }^{2}$ Sistemas de Informação - Universidade Tiradentes (UNIT) - Aracaju, SE - Brasil \\ ${ }^{3}$ Professor Doutor em Ciências - Informática - Universidade Tiradentes (UNIT) - \\ Aracaju, SE - Brasil \\ \{celio.ighour, raffael.castro, nathalia.freitas99, \\ igor.oliveira\} dsounit.com.br
}

\begin{abstract}
This article addresses the dissemination of public data as a mechanism that strengthens democracy. Its availability should occur in a clear way, allowing a greater engagement of society in its reuse in social control projects. The development of creative technological solutions can provide a better manipulation of such data, as the proposed application.
\end{abstract}

Resumo. Este artigo aborda a divulgação de dados públicos como mecanismo fortalecedor da democracia. A sua disponibilização deve ocorrer de maneira clara, permitindo um maior engajamento da sociedade na sua reutilização em projetos de controle social. $O$ desenvolvimento de soluções tecnológicas criativas pode proporcionar uma melhor manipulação de tais dados, a exemplo da aplicação proposta.

\section{Introdução}

A participação popular nos assuntos públicos é uma característica desejável para o bom funcionamento de uma democracia, possibilitando uma maior fiscalização e controle da administração pública.

Tais atos demandam a publicidade dos dados produzidos e manipulados pelo poder público, entregando à sociedade uma maneira de averiguar possíveis irregularidades.

Nesse sentido, o trabalho visa o uso da tecnologia da informação como meio de pesquisa de dados contidos em documentos públicos abertos através de uma plataforma colaborativa.

\section{Descrição do Aplicativo}

A aplicação consiste na proposição de um ecossistema em que os usuários poderão inserir documentos disponibilizados em sítios eletrônicos, processando o seu conteúdo e armazenando em uma base de dados não relacional.

A partir de então, será possível realizar a pesquisa de dados contidos em determinado documento ou grupo de documentos para obtenção de informações e posterior análise do resultado encontrado. 
No momento, o protótipo funciona apenas com documentos no formato commaseparated values (csv) e a visualização do resultado da pesquisa em tabelas e gráficos, bem como ainda não inclui autenticação de usuários, funcionando de maneira que qualquer utilizador pode manipulá-la.

Ressalta-se que o foco da aplicação é a obtenção pelos usuários de documentos divulgados no Portal de Dados Abertos [BRASIL 2019], iniciativa tomada pelo governo brasileiro como membro co-fundador da Parceria para Governo Aberto, incluindo uma interface adicional para a inserção de documentos disponibilizados pelo portal.

\section{Contribuições Tecnológicas}

Conforme o World Wide Web Consortium, os dados abertos públicos são produzidos pelo governo e disponibilizados às pessoas para leitura, acompanhamento e reutilização em outros projetos, produzindo visualizações interessantes e úteis [W3C 2011].

No entanto, o formato de disponibilização, em sua maioria, não permite uma fácil manipulação dos dados e, por isso, torna-os menos transparentes e atrativos para a utilização pela sociedade em geral.

Dessa forma, a divulgação dos dados está submetida a desafios tecnológicos que podem remover o seu potencial de assistência a projetos sociais quando não superados, a exemplo da baixa utilidade dos dados ou péssima legibilidade por máquinas e humanos [TOOTS 2017], demandando soluções criativas para o seu uso efetivo.

O presente trabalho pretende facilitar a obtenção de informações contidas em documentos inseridos na plataforma para utilização em projetos pessoais, de pesquisa, de controle social, dentre outros, ou até mesmo a simples visualização das informações.

\section{Conclusões}

Percebe-se que os dados disponibilizados pelo poder público proporcionam uma fonte de informações a serem utilizadas no desenvolvimento de inúmeros projetos que podem contribuir no controle social e otimização da administração pública.

Com isso, denota-se a importância dessa disponibilização de uma maneira que estimule a sua utilização, necessitando de soluções tecnológicas que permitam usufruir o seu potencial, a exemplo da aplicação proposta no presente trabalho.

\section{Referências}

Brasil (2019). Sobre o dados.gov.br - Portal Brasileiro de Dados Abertos. http://dados.gov.br/pagina/sobre, [accessed on Apr 8].

Toots, M., McBride, K., Kalvet, T. and Krimmer, R. (may 2017). Open Data as Enabler of Public Service Co-creation: Exploring the Drivers and Barriers. In 2017 Conference for E-Democracy and Open Government (CeDEM). https://ieeexplore.ieee.org/document/8046277.

W3C, W. W. W. C.-E. B. (2011). Manual dos Dados Abertos: Governo. http://www.w3c.br/pub/Materiais/PublicacoesW3C/Manual_Dados_Abertos_WEB.pdf. 